\title{
Ethics Criteria for Uterine Transplants: Relevance for Low-Income, Pronatalistic Societies?
}

\author{
Zubia Mumtaz $^{1 *}$ and Adrienne Levay ${ }^{2}$ \\ ${ }^{1}$ Department of Public Health Sciences, University of Alberta, Canada \\ ${ }^{2}$ School of Public Heatlh, University of Alberta, Canada
}

Human uterus transplantation is currently under investigation as a treatment for uterine factor infertility (UFI) [1,2]. After decades of animal research, the first clinical human trials of uterine transplantation (utx), led by Brannstrom and colleagues, started in Sweden in October 2012 [1]. This experimental procedure has generated global media attention and worldwide lay-interest with inquiries and requests for enrolments in the trial from all over the world [3].

Utx technology is the newest advance in the continuously expanding discipline of Assisted Reproductive Technology (ART). It addresses one of the greatest challenges in the treatment of absolute UFI, a common cause of infertility affecting approximately $3-5 \%$ of the general population [4]. Its causes are many and include congenital absence of the uterus (1/5000 newborns) [5], post-partum hysterectomies due to haemorrhage (1 out of 198 caesareans in the US) [6], and radical hysterectomies following invasive cervical cancer (incidence rate of cervical cancer for 2008 was 15.2 per 100,000 globally [7] with about $60 \%$ being amenable to treatment via radical hysterectomy [8]).

Like all scientific advances in the discipline of ARTs, human utx technology poses some complex ethical questions. Some of these relate to the clinical context of the procedure: is it surgically appropriate to perform a highly risky procedure for a non-vital organ? What harm could the transplantation and immunosuppressive drugs pose for the developing fetus, particularly given that the transplanted organ is directly affected by the pregnancy? Other questions refer to donor safety, social impact, and management of health care services, especially with regards to access and cost. A growing body of literature is addressing these issues [9-13].

Missing in this discourse is an analysis of the ethical dilemmas surrounding the transfer to, and the use of utx technology in developing countries. As exhibited previously by the uptake of kidney transplant technology, transfer of the technical aspects of transplantation technology can take place quite rapidly [14]. What remains unaddressed is the application of utx technology and its impact on low-income countries (LICs) countries given their unique conditions. These include fragile, poorly resourced health systems, wide-spread poverty, sharp inequities in access to resources of all kinds, the absence of relevant laws and poor enforcement of existing laws. This article addresses some of these questions taking Pakistan as a case study.

\section{The Pakistan Context}

Infertility is a major reproductive health problem in Pakistan with prevalence estimates ranging from $15-22 \%[15,16]$. While there are no statistics available to our knowledge giving the prevalence of UFI specifically as the cause of infertility in Pakistan, there is evidence that hysterectomies are performed in higher numbers than in high-income countries (HICs). Estimates from Pakistan range from 1 in 139361 [17-19]. In comparison, the frequency of obstetric hysterectomies in Western countries has been found to range from 1 in 2,224 to 1 in 4,4228 [20,21]. Furthermore, anthropological studies from Pakistan suggest the possibility that unnecessary hysterectomies are being performed, particularly among rural women. Women travelling far distances to seek medical services for a variety of reproductive issues encounter doctors who decide that, due to her rural origins, a hysterectomy is the best and most efficient option to solve her issues [22]. Therefore, it could be that the women of Pakistan experience an inordinate burden of UFI.

Pakistan is a particularly pronatalistic society characterised by large family sizes [23]. Childbearing is a universal expectation and is promoted through a set of institutionalized social values, norms and structures. These include children being viewed as providing core meaning to life, required for continuity of the family name [24] and for their instrumental and social assistance in later life [25]. The social ideal for women is to bear four children [26,27], with at least 2 sons [27] . Childlessness in this context is not only unthinkable, it is socially unacceptable and is understood to be a failure to adhere to cultural norms [24]. It is this pronatalism that is partly responsible for the high rates of reported infertility. Infertility in Pakistan does not mean childlessness alone, but also includes not having the right number of children, and more importantly the right 'type' of children, or in other words, the right number of sons [28].

While infertility in Pakistan impacts both men and women [28] it is particularly disastrous for women who experience well-documented negative consequences [29-32]. This is a context in which a woman's identity is solely dependent on her reproductive success [26,33]. Becoming a mother in the first year of marriage is not only highly desirable, it is essential to prove her fecundity and thereby secure her position in the marital household and society [34,35]. Children are believed to bond a husband and wife to one another [35] and therefore childlessness leaves women in precarious and unstable marriages as well as suffering harsh social and sometimes physical consequences [36]. Women experience physical, mental and emotional abuse from husbands and their in-laws [30], taunting and verbal harassment [34], being socially excluded from important events like weddings [37] and from touching babies [36], threatened with divorce and ejection from their marital home or having their husband marry a second wife [30]. The literature has also reported childless women suffering from psychosocial consequences like depression, dejection and suicidal ideation [37].

*Corresponding author: Zubia Mumtaz, Department of Public Health Sciences University of Alberta, 3-309 Edmonton Clinic Health Academy, Canada, Tel: 780.492.7709; Fax: 7804920364; E-mail: zubia.mumtaz@ualberta.ca

Received December 13, 2012; Accepted December 28, 2012; Published December 31, 2012

Citation: Mumtaz Z, Levay A (2012) Ethics Criteria for Uterine Transplants: Relevance for Low-Income, Pronatalistic Societies? J Clinic Res Bioeth S1:004. doi:10.4172/2155-9627.S1-004

Copyright: @ 2012 Mumtaz Z, et al. This is an open-access article distributed unde the terms of the Creative Commons Attribution License, which permits unrestricted use, distribution, and reproduction in any medium, provided the original author and source are credited. 
Infertile women in Pakistan have been found to incessantly seek infertility treatments $[28,38]$, sometimes for up to 20 years and sometimes regardless of whether or not she is the infertile partner in the marriage [28]. They will seek treatments from a range of practitioners from traditional healers to biomedical practitioners [28,38], often undergoing invasive and dangerous treatments [28]. Surrogacy as a treatment option is unthinkable due to the Islamic belief that the only mother who can be considered the true mother of a child is the woman who gives birth [39]. Adoption is also a highly undesirable option as it is not possible for an adopted child to carry on the patriline, or inherit the family property $[40,41]$.

In light of the severe consequences and stigma of infertility coupled with the high prevalence of hysterectomies conducted in Pakistan, the emerging utx technology may become one more, and perhaps the only, option for Pakistani women with UFI. Given the stigma of infertility and the extent to which women are willing to seek treatment, it may also be assumed that uterine transplant technology will be adopted at a much faster rate than expected. This raises ethical questions regarding the use this technology in LIC contexts such as Pakistan. The questions encompass eligibility of recipients, who should donate, who should make these decisions, and who should be allowed to make these decisions? Is there a danger of organ trafficking? There are also questions about the capacity of the nation's health care system to undertake this complex procedure. More importantly, when should such a dangerous, expensive, but non-vital procedure become an acceptable procedure? Should society be allocating its scarce resources to such procedures? How far should a society be willing to go in the pursuit of having children? [42]. We aim to highlight these as-yet undiscussed potential ethical concerns in relation to the possibility of utx in Pakistan with relevance to other nations with similar contexts.

\section{Uterine Transplantation}

The first human utx occurred in 2000 in Saudi Arabia where a 26year old woman had undergone a postpartum hysterectomy due to massive hemorrhage. She received a uterus, and oviducts from a 46 year old live donor [43]. The transplanted uterus had to be removed shortly thereafter due to necrosis. A second known case, which has yet to be published in the scientific literature, occurred in Turkey in 2011 [2]. Currently a clinical trial in Sweden is underway [2] and the first mother-to-daughter transplants have been attempted with no resulting surgical complications. It is believed, because the research is showing promising results in animal models [44], that utx will become a reality and will eventually become the 'gold standard' to treat UFI $[13,45]$.

Utx would be the only alternative for women for whom surrogacy or adoption (currently the only alternatives for UFI) is not feasible for religious [41], ethical [41,46], or legal [47] reasons, as is likely to be the case in countries like Pakistan. Physicians do not agree that utx is superior to surrogacy or adoption as far as risk and expediency [13] but it is the only way in which a woman with UFI could possibly have the experience of carrying a pregnancy. It should be noted that the transplanted uterus will not be enervated, meaning that the recipients will not be able to feel the pregnancy. It has also been proposed that, at least initially, prophylactic caesarean sections would be performed on recipients of uterine transplants, effectively diminishing the experience of pregnancy [48].

\section{Ethical Debates Surrounding Uterine Transplants}

The ethical considerations of underlying utx are complex. In contrast to clearly life-saving transplants (heart, liver) or even kidney and cornea transplants, which remain relatively non-contentious because they are justified by considerations of improvements in quality of life, utx do not address issues of compromised day-to-day physiological functioning. Utx is only intended to improve quality of life. Moreover, women have access to surrogacy and adoption; their children may even be genetically related to them using the current ARTs.

Since utx technologies occupy the ethical intersections of organ transplantation and ART [42], the ethical challenges faced by organ transplantation in general are also applicable here. Questions such as how should uteruses be allocated amidst a limited supply of organs, who should make these decisions, and who should be allowed to donate [42] are as applicable to uterine transplantation as they are to life-saving organs. Nair [45] proposes that uteruses for transplantation should be allocated only to women with UFI and who have no other alternatives. All criteria for who can donate a uterus should remain the same as other types of organ donations apart from some special testing, including Pap tests and Human Papilloma Virus test. Other criteria include donors are between the ages of 16 and 45, with no history of pelvic inflammatory disease, cervical dysplasia, endometriosis, ovarian cancer, or any other anatomical abnormalities. Brain-dead, heart beating, multi-organ donors should be considered acceptable [45].

Lefkowtiz et al. [13] expanded Nair's criteria to include health system capacity. Their proposed "Montreal Criteria for the Ethical Feasibility of Uterine Transplantation" addresses the ethical issues that should be considered prior to undertaking the procedure regarding the recipients, donors, and the treating health care team (Figure 1).

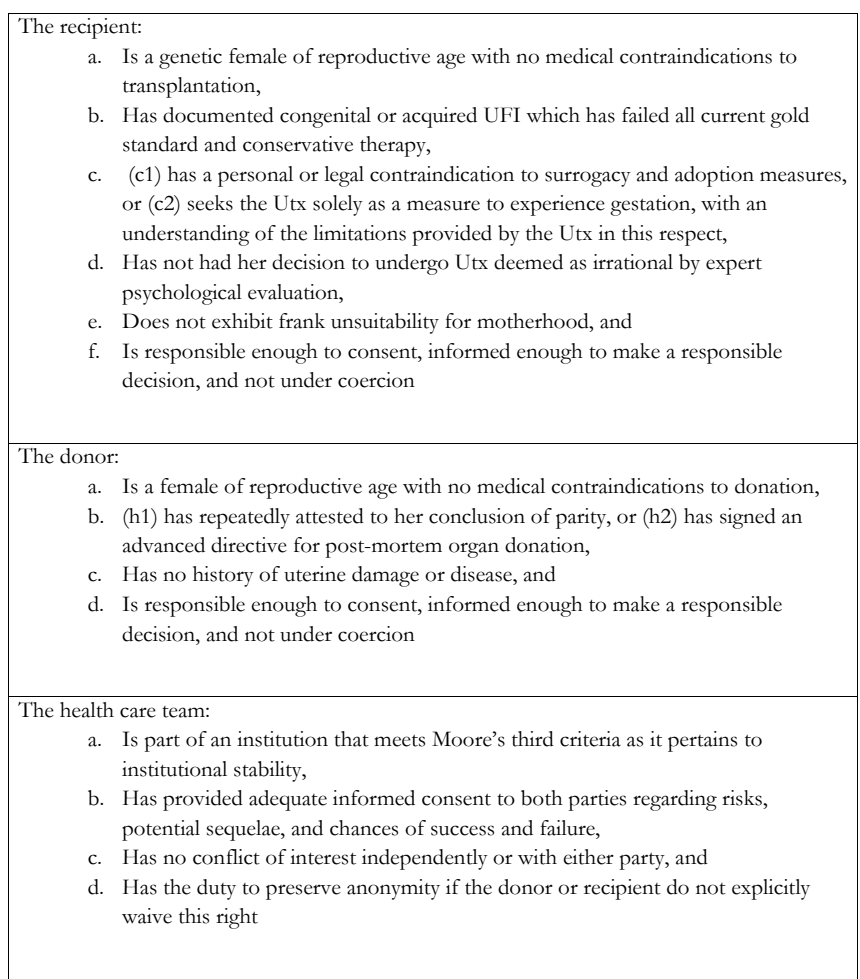

Figure 1: The Montreal Criteria for the Ethical Feasibility of Uterine Transplantation, taken directly from Lefkowitz et al. [13]. 


\section{Pakistan and the Relevance of the Montreal Criteria}

In this section we discuss the applicability of the Montreal Criteria in the Pakistani context. First we will discuss ethical dilemmas surrounding the eligibility of potential recipients of uterine transplants in Pakistan, followed by dilemmas surrounding potential uterus donors and those surrounding health care institutions in Pakistan. We will conclude by discussing the ethics of the transfer of this technology to Pakistan and asking questions as to who or what global or state bodies should be acceptable decision makers in this matter.

\section{The recipient}

Criterion " $\mathrm{f}$ " in figure 1 states that a potential recipient should be "responsible enough to consent, informed enough to make a responsible decision, and not under coercion". For Pakistani women in their marital homes, decisions around seeking infertility treatment lay largely in the hands of their mothers-in-law [24,28]. Research shows that mothers-in-law do not always keep their daughters-in-law's best interests at the forefront in the context infertility decisions. There are reports of mothers-in-law starting to seek infertility treatment for their daughters-in-law sometimes as little as 2 months after the wedding day [28]. Given the mother-in-law's pressure and influence to incessantly seek treatment even in cases of known male infertility, the potential that younger women may be coerced to undergo a utx is a possibility. Rather than focusing on the informed consent of the recipient, it may be the mothers-in-law who must also be informed of the risks and limitations of utx. It should also be kept in mind that simply informing them of the risks and limitations of utx may not be sufficient as their desire to ensure continuity of the family line often trumps their daughter-in-law's well-being [28].

Criterion "d" (Figure 1) states that the potential recipient 'has not had her decision to undergo utx deemed as irrational by expert psychological evaluation'. This may be difficult to implement in Pakistan. The biomedical mental health system in Pakistan is underresourced and not well-established [49]. In 2008 for example, only 3 psychiatrists in total graduated in a country of 180 million people [49] and only $2 \%$ of medical doctors received at least 2 days of a mental health refresher course [49]. There are also issues of what is considered rational and irrational. Rationality and irrationality are subjective notions. A woman seeking to have a child in Pakistan to continue on the family blood line and to ensure her place in her marital household would likely be considered completely rational.

Lastly, criterion " $\mathrm{e}$ " states that the recipient should not exhibit signs that she is unsuitable for motherhood. Obviously there is no indication that Pakistani women are any more or less likely to be 'suitable' mothers than other women in other nations. However, there is the widely acknowledged element of son preference in Pakistan. This could be an ethical dilemma if the main motivation for the procedure is to bear a son. What will happen if the foetus is a female? Will the woman or her marital family make the choice to terminate the pregnancy? Will the woman or her marital family pressure the attending physicians to impregnate the transplanted uterus repeatedly even if it is detrimental to the young woman's well-being? Or will they simply use sex-selection technology to ensure only male embryos are created during in-vitro fertilization [50]. There is a danger that utx technology can become one more vehicle for the practice of sex selective pregnancies and abortions for families to ensure they have a male child and heir.

\section{The donor}

Almost of all of the criteria laid out in the Montreal Criteria regarding donors may be difficult to implement in Pakistan. Pakistan has been termed an 'organ bazaar' where many body organs can be bought or sold. A key reason for this is widespread, multi-dimensional poverty in which historical inequities in land distribution coupled with structural oppression place some groups of people highly vulnerable to exploitation for body organs [51].

Organ trafficking refers to the unjust practice of 'using a vulnerable segment of a country or population (defined by social status, ethnicity, gender or age) as s source of organs' (p.48) [52]. Organ vending is beneficial only to rich people, both locals and, increasingly, foreigners [53]. The most common organs sold are the kidneys. Despite the recent enactment of the law in 2007 banning organ trafficking, newspaper reports from Pakistan suggest that at least 450 people have sold their kidneys in Punjab alone [54]. The majority of Pakistanis who sell their kidneys (93\%) [55] do so to pay off debt to money lenders and sometimes to cover costs of things like weddings [51]. Research shows that the majority of kidney sellers still find themselves in the same poor socioeconomic situation that led them initially to sell their kidneys. The exploitation is exhibited by the fact that while foreign recipients are paying upwards of 40,000 USD for a transplant, the kidney donor only receives a maximum of 2,500 USD [56]. The structural violence perpetuated by Pakistani institutions that maintains high levels of poverty leading to a disproportionate amount of kidneys beings bought from the poor and marginalized, continues to feed the global organ trade.

The history of organ transplant ion in Pakistan leads us to wonder if utx technology might become another vehicle to exploit and abuse poor women. If kidney sellers receive 2,500 USD for a kidney, an organ not involved with creating life for carrying on the patriline, it is likely that uteruses would sell for an even higher rate. It is conceivable that impoverished families might coerce their daughters and wives to donate their uteruses to pay off debts. Bonded labourers might be obliged to provide their 'master's' wives and daughters with uteruses. Until the health system in Pakistan is stringently regulated and the laws illegalizing the organ trade are actually implemented, there could be serious ethical dilemmas with respect to uterus donors and the protection of women's human rights.

\section{The health care team}

The health system requirements for uterine transplants outlined in the Montreal Criteria may also be difficult for the current Pakistani health care system to meet. Generally the health care system in Pakistan is fragile and under-funded. Its privatization has been aggressively pursued since the 1990's with the result that almost $80 \%$ of all health care in Pakistan's is provided by this largely unregulated sector [57] Not surprisingly, most transplant surgeries are performed in the forprofit private sector. Most of these transplant units are not accredited and do not adhere to international standards of safety and quality [58]. Competencies and qualifications vary from practitioner to practitioner and institution to institution; the facilities are often outdated and practices are largely price-driven [55]. Furthermore, malpractice and 'unjust' behaviours by medical professionals have been reported where some Pakistani clinics were found to be, as discussed above, charging 40,000 USD to transplant patients remunerating only about 2500 USD to donors [56,59]. After the law making kidney trading illegal was enacted in 2007, 10 hospitals in Lahore were found to have been involved in black market organ trading [60]. Until there is an increase in overall stability and regulation of the health care system, as well as disincentives to earn income from the organ trade, uterine transplantation in this context remains ethically indefensible. 


\section{Ethics of Technology Transfer: Who Decides?}

What the Montreal Criteria do not address is the ethics of transferring utx technology to low-income, pronatalistic, highly patriarchal societies. As discussed above, there exists potential for increased 'bioviolence' [61] or structural violence [62] in Pakistan with the emergence of this new transplant technology which could further disadvantage poor, marginalized and already-exploited Pakistani women. This leads to questions about whether such a dangerous and expensive, but non-vital procedure should be introduced at all in Pakistan. As asked above, how far should a society be willing to go in the pursuit of having children? Who should decide the answers to these questions?

Hellsten [63] argues that the advances in biotechnology have created previously unimaginable possibilities which past hegemonic moral frameworks and traditional medical ethics, valuing the principles of beneficence, non-malfeasance, justice, and autonomy, are no longer are sufficient to address. Now, as biotechnological advancements are no longer impeded by national boundaries, there is a need for incorporating an international dimension that critically reflects on the unique contexts that exist globally [64]. To address this, ethicists have called for transdisciplinary engagement in reflective debates surrounding bioethics [64,65], a 'critical bioethics' [66] and an 'anthropologically informed bioethics' [67].

Given the potential of uterine transplant technology to cross national boundaries and encroach on women's human rights in places where they already have little decision-making power or rights, the technology itself becomes a global human rights issue. This leads to deeper questions: who is to decide that one country is 'safe enough' or has a 'high enough' level of gender equality that utx could be ethically defensible while another is simply 'not good enough' yet to allow this technology? It would be possible to incorporate into ethical criteria a critical assessment of the level of governance and the human rights record of a nation when deciding when and how to incorporate particular biotech advances. However, this could lead to the creation of a double standard whereby some countries will allow themselves the benefits of a technology while condemning other nations for doing the same.

Given the potential negative impact utx technology could have in patriarchal and hierarchical countries like Pakistan and other LICs, where child bearing is of the utmost importance for women's existence and where women are devalued citizens, the question that arises is: should this technology be developed all? This is not a radical question as uterine transplants are not an essential, life-saving procedure [48].

Traditionally the scope of bioethics has been limited to the acceptance of the social order, lacking any dimension of social justice [68], and neglects the ways in which institutional configurations perpetuate poverty, disempower people and subsequently propagate existing social hierarchies [68]. Parker [69] calls for a bioethics that analyses issues through the lens of socially constructed vulnerability and power. Structural violence, the manner in which social arrangements impact an individual's and a population's agency, must also be considered in bioethical debates [68] which includes axes at the individual level (eg. ethnicity, gender) and at the population level (eg. institutional oppression, including institutionalized gender) [70].

The purpose of this paper was to propose the potential bioethical implications involved with the emergence of utx in the context of a patriarchal, hierarchical, and pronatalistic LIC. What is currently emerging in conjunction with developments in utx technology are ethical criteria and discussions which are largely western-centric, where reasonably high levels of gender equity and equality exist and where health systems are highly regulated and laws are strongly implemented. We argue that these emerging criteria founded on the traditional medical bioethical principles of autonomy, nonmalfeasance, beneficence, and justice, do not capture either the unique contexts of women globally nor contexts of structural violence which can be exacerbated by these emergent biotechnologies.

\section{Acknowledgment}

ZM is currently funded by the Alberta-Innovates Health Solutions through its Alberta Heritage Foundation for Medical Research Population Health Investigato Awards.

\section{References}

1. Brännström M, Diaz-Garcia C, Hanafy A, Olausson M, Tzakis A (2012) Uterus transplantation: animal research and human possibilities. Fertil Steril 97: 12691276.

2. BBC News (2012) Mother-to-daughter womb transplant 'success' in Sweden.

3. Lilja J, Nordenvall KJ, Bränström M (1982) Dentin sensitivity, odontoblasts and nerves under desiccated or infected experimental cavities. A clinical, light microscopic and ultrastructural investigation. Swed Dent J 6: 93-103.

4. Milliez J (2009) FIGO committee for the ethical aspects of human reproduction and women's health. Int J Gynaecol Obstet 106: 270

5. Edmonds DK (2003) Congenital malformations of the genital tract and thei management. Best Pract Res Clin Obstet Gynaecol 17: 19-40.

6. Shellhaas C (2001) The MFMU cesarean registry: cesarean hysterectomy--its indications, morbidities and mortality. Bethesda, MD: For the NICHD MFMU Network.

7. Jemal A, Bray F, Center MM, Ferlay J, Ward E, et al. (2011) Global cancer statistics. CA Cancer J Clin 61: 69-90.

8. Engle DB, Connor JP, Morris PC, Bender DP, De Geest K, et al. (2012) Intraoperative autologous blood transfusion use during radical hysterectomy for cervical cancer: long-term follow-up of a prospective trial. Arch Gynecol Obstet 286: 717-721.

9. Carter J, Sonoda Y, Baser RE, Raviv L, Chi DS, et al. (2010) A 2-yea prospective study assessing the emotional, sexual, and quality of life concerns of women undergoing radical trachelectomy versus radical hysterectomy for treatment of early-stage cervical cancer. Gynecol Oncol 119: 358-365.

10. Sozeri-Varma G, Kalkan-Oguzhanoglu N, Karadag F, Ozdel O (2011) The effect of hysterectomy and/or oophorectomy on sexual satisfaction. Climacteric 14: $275-281$

11. Murphy TF (2010) The ethics of helping transgender men and women have children. Perspect Biol Med 53: 46-60.

12. Caplan AL, Perry C, Plante LA, Saloma J, Batzer FR (2007) Moving the womb. Hastings Cent Rep 37: 18-20.

13. Lefkowitz A, Edwards M, Balayla J (2012) The Montreal Criteria for the Ethical Feasibility of Uterine Transplantation. Transpl Int 25: 439-447.

14. Scheper-Hughes N (2003) Rotten trade: Millennial capitalism, human values and global justice in organs trafficking. J Human Rights 2:197-226.

15. Hardee K, Leahy E (2008) Population, fertility and family planning in Pakistan A program in stagnation. Population Action International.

16. United Nations Population Fund (2003) Pakistan population assessment Government of Pakistan.

17. Najmi RS (1994) Caesarean and postpartum hysterectomy-- a study from Lahore. J Coll Physicians Surg Pak 4:120-125

18. Begum I, Khan A, Khan S, Begum S (2004) Caesarean and post partum hysterectomy. Pak J Med Res 43.

19. Ehsan N, Mehmood A (1998) Emergency peripartum hysterectomy: a study of 96 cases. Pak J Surg 14: 45-49.

20. Gould DA, Butler-Manuel SA, Turner MJ, Carter PG (1999) Emergency obstetric hysterectomy - an increasing incidence. J Obstet Gynaecol 19: 580-583. 
Citation: Mumtaz Z, Levay A (2012) Ethics Criteria for Uterine Transplants: Relevance for Low-Income, Pronatalistic Societies? J Clinic Res Bioeth S1:004. doi:10.4172/2155-9627.S1-004

Page 5 of 5

21. Zorlu CG, Turan C, Isik AZ, Danisman N, Mungan T, et al. (1998) Emergency hysterectomy in modern obstetric practice. Changing clinical perspective in time. Acta Obstet Gynecol Scand 77: 186-190.

22. Towghi $F$ (2012) Cutting inoperable bodies: particularizing rural sociality to normalize hysterectomies in Balochistan, Pakistan. Med Anthropol 31: 229 248

23. National Institute of Population (NIPS) [Pakistan] Studies, Macro International Inc. (2008) Pakistan Demographic and Health Survey 2006-07. Islamabad, Pakistan: National Institute of Population Studies and Macro International Inc.

24. Hampshire KR, Blell MT, Simpson B (2012) ‘Everybody is moving on': infertility, relationality and the aesthetics of family among British-Pakistani Muslims. Soc Sci Med 74: 1045-1052.

25. Dyson T, Moore M (1983) On kinship structure, female autonomy, and demographic behaviour in India. Population and Development Review 9: 35-60.

26. Winkvist A, Akhtar HZ (2000) God should give daughters to rich families only: attitudes towards childbearing among low-income women in Punjab, Pakistan. Soc Sci Med 51: 73-81.

27. MumtazZ(2002) Gender and reproductive health: a need for reconceptualization. Unpublished Ph. D. thesis submitted to the London School of Hygiene and Tropical Medicine.

28. Mumtaz Z, Shahid U, Levay A (2012) Understanding the impact of gendered roles on the experiences of infertility amongst men and women in Punjab [Unpublished manuscript]

29. Leung TW, Ng EH, Leung WC, Ho PC (2003) Intimate partner violence among infertile women. Int J Gynaecol Obstet 83: 323-324

30. Sami N, Ali TS (2006) Psycho-social consequences of secondary infertility in Karachi. J Pak Med Assoc 56: 19-22.

31. Sami N, Ali TS (2012) Domestic violence against infertile women in Karachi, Pakistan. Asian Review of Social Sciences 1:15-20.

32. van Balen F, Bos HMW (2010) The social and cultural consequences of being childless in poor-resource areas. ObGyn Monograph: 1-16.

33. Mumtaz Z, Salway SM (2007) Gender, pregnancy and the uptake of antenatal care services in Pakistan. Sociol Health IIIn 29: 1-26.

34. Bhatti F, Jeffery R (2012) Girls' schooling and transition to marriage and motherhood: exploring the pathways to young women's reproductive agency in Pakistan. Comp Edu 48:149-166.

35. Qadir F, de Silva P, Prince M, Khan M (2005) Marital satisfaction in Pakistan: a pilot investigation. Sexual and Relationship Therapy 20:195-209.

36. Family Health International: Network (2003) preserving fertility. North Carolina: Family Health International.

37. Sami N, Ali TS (2012) Perceptions and experiences of women in Karachi, Pakistan regarding secondary infertility: results from a community-based qualitative study. Obstet Gynecol International 2012: 1-7.

38. Bhatti LI, Fikree FF, Khan A (1999) The quest of infertile women in squatter settlements of Karachi, Pakistan: a qualitative study. Soc Sci Med 49: 637-649.

39. Fadel HE (2002) The Islamic viewpoint on new assisted reproductive technologies. Fordham Law Rev 30:145-157

40. Ali TS, Sami N (2007) Adoption practices among couples with secondary infertility in Karachi: a triangulation study design. J Pak Med Assoc 57: 55-59.

41. Inhorn MC (2006) He won't be my son. Med Anthropol Q 20: 94-120.

42. Blake V, Shah K (2012) Reproductive tissue transplants defy legal and ethical categorization. American Medical Association Journal of Ethics 14: 232-236.

43. Fageeh W, Raffa $H$, Jabbad $H$, Marzouki A (2002) Transplantation of the human uterus. Int J Gynaecol Obstet 76: 245-251.

44. Ramirez ER, Ramirez Nessetti DK, Nessetti MB, Khatamee M, Wolfson MR, et al. (2011) Pregnancy and outcome of uterine allotransplantation and assisted reproduction in sheep. J Minim Invasive Gynecol 18: 238-245.
45. Nair A, Stega J, Smith JR, Del Priore G (2008) Uterus transplant: evidence and ethics. Ann N Y Acad Sci 1127: 83-91.

46. Inhorn MC (2006) Making Muslim babies: IVF and gamete donation in Sunn versus Shi'a Islam. Cult Med Psychiatry 30: 427-450.

47. Sharma BR (2006) Forensic considerations of surrogacy -- an overview. J Clin Forensic Med 13: 80-85.

48. Catsanos R, Rogers W, Lotz M (2011) The ethics of uterus tranplantation Bioethics 2011.

49. World Health Organization (2009) WHO-AIMS report on mental health system in Pakistan: a report of the assessment of the mental health system in Pakistan using the World Health Organization-Assessment Instrument for Mental Health Systems (WHO-AIMS). Islamabad, Pakistan: Ministry of Health, Pakistan.

50. World Health Organization (2012) WHO: Gender and Genetics.

51. Moazam F, Zaman RM, Jafarey AM (2009) Conversations with kidney vendors in Pakistan: an ethnographic study. Hastings Cent Rep 39: 29-44.

52. Budiani-Saberi DA, Karim KA (2009) The social determinants of organ trafficking: a reflection of social inequity. Social Medicine 48: 48-51.

53. United Network for Organ Sharing (2007) UNOS Board Further Addresses Transplant Tourism.

54. llyas $F$ (2012) Alarm over organ trade resurgence.

55. Akoh JA (2011) Renal transplantation in developing countries. Saudi J Kidney Dis Transpl 22: 637-650.

56. Garwood P (2007) Dilemma over live donor transplantation. B World Health Organ 85:5-6.

57. Federal Bureau of Statistics (2005) Pakistan social and living standards measurement survey 2004-05. Islamabad, Pakistan: Federal Bureau of Statistics.

58. Donahue KT, vanOstenberg P (2000) Joint Commission International accreditation: relationship to four models of evaluation. Int J Qual Health Care 12: $243-246$

59. IRIN (2007) Pakistan: Government mulls new law on illegal kidney sales.

60. Kazim SF (2008) Organ donation law in Pakistan: an overview of the current situation. J Pak Med Assoc 58: 99-100.

61. Moniruzzaman M (2012) "Living cadavers" in Bangladesh: bioviolence in the human organ bazaar. Med Anthropol Q 26: 69-91.

62. Galtung J (1969) Violence, peace, and peace research. J Peace Res 6: 167191

63. Hellsten SK (2008) Global bioethics: utopia or reality? Dev World Bioeth 8 : 70-81.

64. Kutukdjian $\mathrm{G}$ (2009) The bioethics debate: transdisciplinary requirements in the multicultural context. J Int Bioethique 20: 31-40.

65. Marshall P, Koening B (2004) Accounting for culture in a globalized bioethics. $J$ Law Med Ethics 32: 252-266.

66. Hedgecoe AM (2004) Critical bioethics: beyond the social science critique of applied ethics. Bioethics 18: 120-143.

67. Koening BA, Marshall PA (2003) Anthropology and bioethics. In Encyclopedia of Bioethics (3rd edn). edited by Post SG New York: Thomson Gale, Macmillan Reference 215-225.

68. Azetsop J (2011) New directions in African bioethics: ways of including public health concerns in the bioethics agenda. Dev World Bioeth 11: 4-15.

69. Parker LS (2007) Bioethics as activism. In The Ethics of Bioethics. Mapping the Moral Landscape. edited by Eckenwiler LA, Cohn FG Baltimore, MD: John Hopkins University Press 144-157.

70. Farmer $P$ (2009) On suffering and structural violence: a view from below. Race/ Ethnicity: Multidisciplinary Global Contexts 3: 11-28. 